\author{
Clinical note
}

\title{
THE SPECTRAL PROPERTIES OF HIPPOCAMPAL EEG RELATED TO BEHAVIOUR IN MAN $^{\prime}$
}

D.E.A.T. ARNOLDS ${ }^{2}$, F.H. LOPES DA SILVA, J.W. AITINK, A. KAMP and P. BOEIJINGA

Brain Research Department, Institute of Medical Physics TNO, National Health Research Organization, P.O. Box $5011,3501 \mathrm{JA}$ Utrecht (The Netherlands)

(Accepted for publication: June 24, 1980)

In a number of mammals increases have been observed of the hippocampal slow wave activity in the theta band in relation to various aspects of behaviour such as orientation (Grastyán et al. 1959), attention and arousal (Kemp and Kaada 1975) and motor behaviour (Lopes da Silva and Kamp 1969; Arnolds et al. 1979a,b,c). Similar relations have up till now not been reported in humans. Recently Halgren et al. (1978) concluded that the human hippocampal EEG tends to desynchronize during attentiveness and movement, quite in contrast to the results of the animal experiments. We were able to obtain some records of the human hippocampal EEG during a number of well defined behaviours thanks to the cooperation of a patient with epilepsy who had been implanted with electrodes in various brain structures, among them the hippocampus, in an attempt to localize a possible focus of epileptic activity; this was of essential importance in order to plan a neurosurgical intervention. The investigation of the hippocampal EEG during different behavioural states was carried out in the hope of obtaining electrophysiological evidence regarding the accuracy of the electrode position. A sensitive method for the analysis of the spectral characteristics of the EEG in relation to behaviour allowed us to find relations between the human hippocampal EEG and behaviour comparable to those found in other mammals.

\footnotetext{
1 The investigations were supported (in part) by the Foundation for Medical Research FUNGO, which is subsidized by the Netherlands Organization for the Advancement of Pure Research (ZWO).

2 Reprint requests to $D$. Arnolds, Institute of Medical Physics TNO, 45 Da Costakade, 3521 VS Utrecht, The Netherlands.
}

Materials and Methods

Brief case history

The patient (P.J.H.-V.) is a left-handed woman suffering from psychomotor seizures since the age of 18. The seizures are characterized by impairment of consciousness and psychomotor automatisms followed by a state of confusion. They occurred typically in short series of 3 or 4 seizures on successive days; the intervals between the series were of about 5 weeks. Scalp EEGs showed marked paroxysmal activity maximal over the right fronto-temporal area. Computer tomography showed no clear abnormalities except for a slight enlargement of the right sylvian fissure. The diagnosis was 'partial seizures with complex symptomatology' probably localized in the right fronto-temporal hemisphere. Considering that the seizures were not controlled by several types of pharmacological treatment it was decided to investigate whether a lobectomy would be indicated. Chronically indwelling electrodes were placed by Dr. C.W.M. van Veelen, as described elsewhere (Lopes da Silva et al. 1977): 4 pairs of subdural bundles were implanted over the right and left fronto-orbital, fronto-lateral, temporal and parieto-occipital areas; 2 pairs (right and left) of intracerebral bundles were implanted in the pes hippocampus and amygdala. The subdural bundles consisted of seven $150 \mu \mathrm{m}$ stainless steel wires insulated from $5 \mathrm{~mm}$ at the tip with interelec. trode distances of $10 \mathrm{~mm}$; the intracerebral bundles, from which the results reported here were recorded, consisted also of seven $150 \mu \mathrm{m}$ stainless steel wires, but with a smaller uninsulated contact surface (length $2.5 \mathrm{~mm}$ ) and a shorter interelectrode distance (2.5 $\mathrm{mm}$ ). Twenty-three registrations with a duration of $2-4 \mathrm{~h}$ each and one lasting 4 days were carried out using the intracranial electrodes. In this way electrocorticograms were obtained during 7 seizures. These ECoGs from the right derivations showed a marked decrease in amplitude and large spike and wave complexes over the mid-temporal area preceding the elec- 
tro-clinical seizure. The electrocorticographic seizure patterns varied so that the location of a clearly defined trigger zone could not be found. For this reason it was decided that a lobectomy should not be carried out.

The spectral analysis of EEGs (epochs $100 \mathrm{sec}$ long) recorded from the bundles of electrodes aimed at the right $(R)$ pes hippocampus while the subject was alert but at rest, revealed clear differences between several regions: the spectra of EEGs recorded from the 2 most dorsal electrodes (R6.8, R6.9 located in the basal ganglia) showed a peak at $2.8 \mathrm{~Hz}$; the spectra of 2 others (R6.10, R6.11) which, on the basis of stereotaxic coordinates, were considered to lie in the pes hippocampus, had a peak at 3.5 $\mathrm{Hz}$; the 3 deepest (R6.12, 6.13, 6.14) electrodes (located in the infero-temporal cortex) showed a rather broad and less well defined peak with a maximum around $3 \mathrm{~Hz}$. The linear coherence between the signals recorded from $R 6.10$ and $R 6.11$ reached the value of 0.89 , whereas between $R 6.10$ and $R 6.9$ it was 0.74 and between $R 6.10$ and R6.12 it was 0.38 . Given these electrophysiological and stereotaxic data we assumed that $T 6.10$ and $R 6.11$ were records from the pes hippocampus and that both presented almost the same information; thus the signals from R6.10 were used for the investigation reported here. The contralateral bundle, however, was not precisely symmetrically placed; its tip was much more medial than on the right side. The spectra of the corresponding EEGs did not show a clear peak at $3.5 \mathrm{~Hz}$ but at about $3.0 \mathrm{~Hz}$; the linear coherence between the signal from R6.10 and the contralateral corresponding signals was only 0.3 . Thus we assumed that the electrodes aimed at the left pes hippocampus did not reach the desired structure in an optimal way.

\section{Experimental plan}

Recording was against a fronto-polar intracranial electrode. All relevant signals were recorded on 14 channel FM tape along with a time code. The patient was recorded during two different days (session I and II). She was free to move around since we made use of a radio telemetry system to transmit EEG signals as well as the output of a small accelerometer, which was used as a movement indicator.

The spectral properties of the hippocampal EEG were investigated in relation to the execution of two behavioural tasks. In the first the patient was seated in a darkened room and was presented with a series of slides representing simple objects. She was instructed to walk $( \pm 4 \mathrm{~m})$ towards a blackboard mounted next to the projection screen after the projection of each slide, to write on it the name of the object, to walk back and to sit down again. This task was performed twice on each of the two experimental days, once while the subject was instructed to walk briskly (experiments I.1 and II.1) and once while she per- formed the task at a normal pace (experiments I.2 and II.2). The second task was purely verbal. At each trial the subject was presented with the name of an entity and required to name the class to which it belonged (e.g., question: 'Amsterdam', answer: 'city'). In a second series of questions the problem was reversed (e.g., question: 'a vegetable', answer: 'cabbage'). Since the results in both series were comparable the data of these two series of questions were pooled, thus yielding experiment II.3. During the recording session I the subject was on $300 \mathrm{mg}$ sodium valproate ( 3 times/day) and $200 \mathrm{mg}$ carbamazepine ( 4 times/day). During recording session II she was on $300 \mathrm{mg}$ sodium valproate (twice/day).

\section{Analysis}

A computer system was used for the analysis of relations between behavioural data and spectral EEG parameters. With this system the values of EEG and behavioural parameters, measured during a number of realisations of the same type of behaviour were averaged. As EEG parameters we used the amplitude spectrum of the EEG and 3 spectral parameters derived from the amplitude spectrum, i.e., the index of peak frequency $\left(I_{P F}\right)$, the amplitude in a $3 \mathrm{~Hz}$ wide band around the peak frequency $\left(I_{A M}\right)$ and the index of rhythmicity $\left(\mathrm{I}_{R}\right)$ which was found by dividing the amplitude within the $3 \mathrm{~Hz}$ band around the peak frequency by the amplitude of the other spectral frequency components. The integrated output of the accelerometer used as a movement indicator provided the single behavioural parameter in this study. Also the average value of each of these parameters as a function of time was computed in relation to a certain trigger point. For a more precise account of this method of analysis see Arnolds et al. (1979a).

\section{Results}

\section{Experiments I.1, I.2, II.1 and II.2}

The right (R) hippocampus (R6.10) revealed a field potential characterized by an irregular rhythmic component at $3-4 \mathrm{c} / \mathrm{sec}$ (Fig. 1.). From the left (L) hippocampal electrode a signal of smaller amplitude and rhythmicity was derived. Behaviour-related changes in these signals became apparent upon statistical analysis. Only in the signal from the $R$ hippocampus was a clear-cut reactivity found. Hence the results presented below all pertain to this derivation.

We selected from experiments I.1 and I.2 and from II.1 and II. 2 a number of periods during which the subject was in a clear behavioural state: (a) walking towards the blackboard, (b) writing, (c) walking back, and (d) sitting; we determined the average value of the spectral parameters and of the integrated output of the movement transducer during these behavioural states (Fig. 1). The value of the spectral parameters 


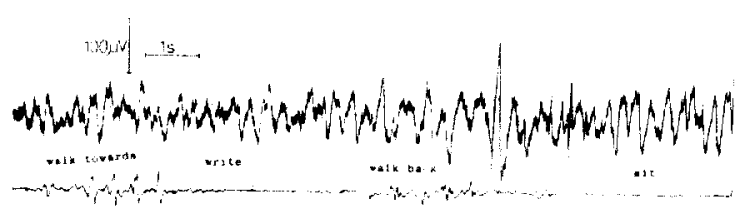

FAST
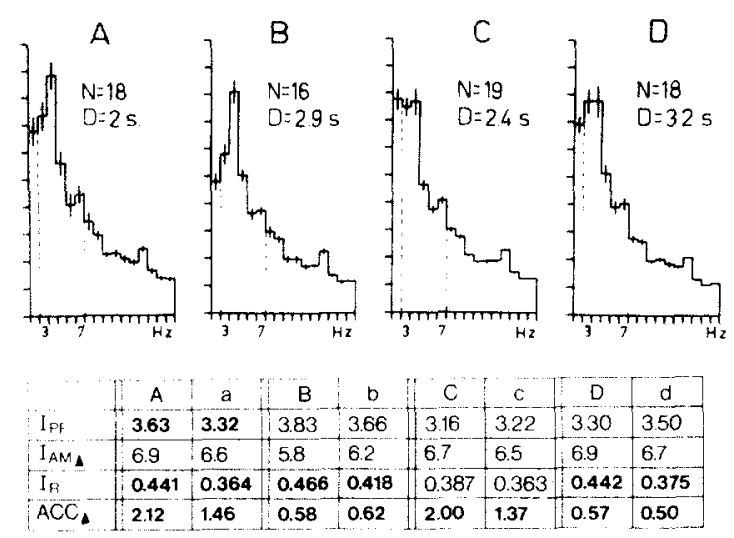

$$
\begin{array}{|l|l|l|l|l|l|l|l|l|}
\hline I_{P F} & 3.40 & 3.31 & 3.95 & 3.64 & 3.58 & 3.50 & 3.64 & 3.45 \\
\hline I_{A M} & 5.5 & 5.4 & 5.5 & 53 & 6.0 & 5.4 & 6.3 & 5.7 \\
\hline I_{F} & 0.328 & 0.331 & 0.363 & 0.351 & 0.352 & 0.368 & 0.382 & 0.354 \\
\hline A C C, & 2.86 & 1.76 & 0.86 & 0.74 & 2.22 & 1.40 & 0.660 & 0.659 \\
\hline
\end{array}
$$

Fig. 1. Above: example of the hippocampal EEG recorded during a single trial of experiment I.1. Below: average power spectra of the hippocampal EEG recorded during each of the 4 behavioural states in experiment 1.1 , i.e., A: walking towards blackboard; $\mathrm{B}$ : writing; $\mathrm{C}$ : walking back; $\mathrm{D}$ : sitting. $\mathrm{N}$ is the number of averaged periods. $D$ is the average $d u$ ration of these periods. The tables give the average values of the spectral parameters and the movement parameter (ACC) during the 4 behavioural states, as recorded during sessions I and II. Columns headed by capital letters refer to the 'brisk' (1) version of the behaviour, lower case letters to the moderate (2) version. When a pair of values is written in bold characters this indicates that the difference between values is statistically significant ( $P<0.05$, Wilcoxon test). A indicates arbitrary scaling. Parameters so designated cannot be compared across experiments.

appeared to be generally higher during 'the brisk' than during 'the moderate' version of the same behaviour (see Fig. 1). Comparison of the spectral parameter values associated with different behavioural states revealed a consistent difference between 'writing' and the other 3 behaviours. $I_{P F}$ and $I_{R}$ during writing were relatively high, while $I_{A M}$ was relatively low (Wilcoxon $P<0.05$ ). As shown in Fig. 1 the same trends were visible in both sessions I and II. The rhythmicity of the signal was consistently lower dur-
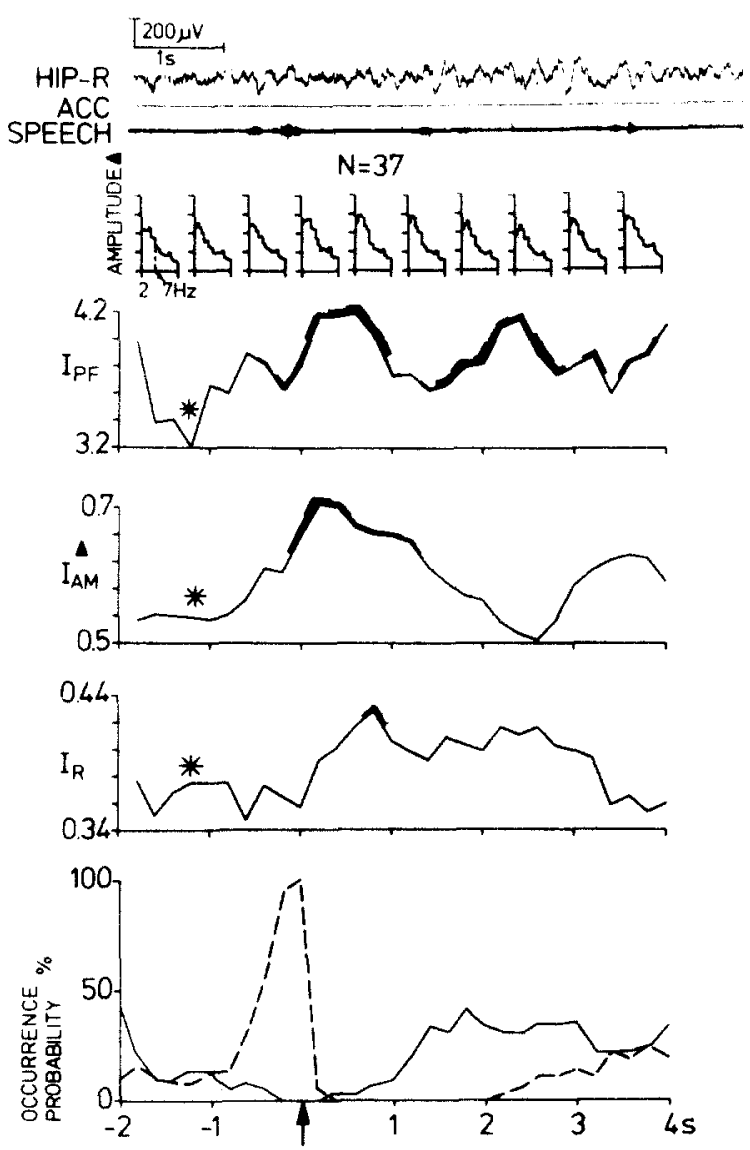

Fig. 2. The upper trace gives the hippocampal EEG during a single trial of experiment II.3 (question: 'Amsterdam', answer given by the subject: 'the capital'). HIP-R = hippocampal EEG; ACC = output of movement transducer on subject; $S P E E C H=$ recording of speech of experimenter and subject. The series of histograms represents the average running spectral analysis of the hippocampal EEG during experiment II.3. Each histogram concerns a $200 \mathrm{msec}$ time bin. Interhistogram distance $600 \mathrm{msec}$. Spectra to be averaged have been aligned with respect to the trigger point: the end of the keyword. The 3 following curves show the average $I_{P F}, I_{A M}$ and $I_{R}$ as a function of time in relation to this trigger point (arrow). Where the curve is thickened there exists a statistically significant difference between that part of the curve and the point indicated by an asterisk, chosen as a reference (sign test). The thicker the line the higher the significance of the statistics (lowest level $P<0.05$; highest $P<0.001)$. The lowermost curve indicates the probability that the experimenter (stippled line) or the subject (full line) was talking, aligned with respect to the trigger point. No significant fluctuations were found in the output of the movement transducer (hence not shown). 
ing session II than during session I however (Wilcoxon $P<0.05$ ).

\section{Results of experiment II.3}

The word association tasks used were designed with the object of having one cue word spoken by the experimenter and, in response, a single word uttered by the subject. Since the subject did not always restrict herself to a single word response, the best defined trigger point was the end of the cue word spoken by the experimenter.

Fig. 2 shows the spectral parameters as a function of time in relation to the end of the keyword. It is remarkable that all spectral parameters increase significantly in the period of silence between 'question' and 'answer'. Furthermore, when some epochs of talking and listening recorded during informal conversations were compared, $\mathrm{I}_{\mathrm{AM}}$ was significantly lower while the subject talked than while she was only listening $(P<0.05$, Wilcoxon $)$.

\section{Discussion}

It is remarkable that the values of the spectral parameters of the theta component in the human hippocampal EEG were consistently higher when associated with the more intense performance of a certain behaviour. This outcome is fully in accord with the facts observed in dog (Arnolds et al. 1979a, b,c). A striking discrepancy with animal data is, however, the lack of a relationship between gross motor activity (walking vs. sitting) and the spectral properties of the human hippocampal EEG. The variations in the spectral properties appear to be associated largely with what could be called verbal behaviour, be it writing or speaking. Possibly this finding points in the direction of an involvement of the hippocampus in linguistic processes (O'Keefe and Nadel 1978).

The effects described here are of course no more than a consistent relation between EEG and behavioural events. This does not imply a link of causality. Possibly both events have simply as a common cause the neural activity of brain stem areas concerned with sensorimotor coordination which project to the hippocampus by way of the septal area.

\section{Summary}

In an epileptic patient with depth electrodes placed in the hippocampal formation we observed the following:

(i) There existed a significant peak in the theta band of the hippocampal EEG of this subject under a number of behavioural circumstances.

(2) Four different behaviours were performed at two degrees of intensity. Whenever the values of a certain spectral parameter associated with a low or a high intensity behaviour showed a significant difference, the higher value corresponded with the more intense version of the behaviour.

(3) The frequency and rhythmicity of the hippocampal theta component during writing was consistently higher than during sitting or walking. The amplitude was smaller.

(4) In a word association task the amplitude, frequency and rhythmicity showed a significant rise during the period of silence immediately following the question and preceding the answer.

\section{Résumé}

Caractéristiques spectrales de l'EEG de l'hippocampe en relation avec le comportement chez l'homme

Chez une patiente épileptique porteuse d'électrodes profondes à demeure dans la formation hippocampique nous avons observé les faits suivants:

(1) Il existait un pic significatif de l'EEG hippocampique dans la bande thêta dans un certain nombre de situations comportementales.

(2) On a fait exécuter 4 comportements différents avec 2 degrés d'intensité. Chaque fois qu'il y avait une différence significative entre les valeurs d'un paramètre spectral donné, selon que le comportement était d'intensité faible ou élevée, la valeur la plus haute correspondait au degré le plus élevé d'intensité du comportement.

(3) La fréquence et la rythmicité de la composante thêta hippocampique étaient régulièrement plus élevées lorsque la malade écrivait que lorsqu'elle était assise ou marchait; cependant l'amplitude était plus basse.

(4) Dans une tâche d'association verbale, l'amplitude, la fréquence et la rythmicité augmentaient de façon significative durant la période de silence qui suivait immédiatement la question et précédait la réponse.

We thank Prof. Dr. W. Storm van Leeuwen, Dr. C.W.M. van Veelen and Dr. K. van Hulten for the possibility of examining one of their patients. We also thank Mr. F.W. de Quartel for his help with the stereotaxy and $\mathrm{Mr}$. W. ten Broeke for help with the computer analysis.

\section{References}

Arnolds, D.E.A.T., Lopes da Silva, F.H., Aitink, J.W. and Kamp, A. Hippocampal EEG and behaviour in dog. I. Hippocampal EEG correlates of gross mo- 
tor behaviour. Electroenceph. clin. Neurophysiol., 1979a, 46: 552-570.

Arnolds, D.E.A.T., Lopes da Silva, F.H., Aitink, J.W. and Kamp, A. Hippocampal EEG and behaviour in dog. II. Hippocampal EEG correlates with elementary motor acts. Electroenceph. clin. Neurophysiol., 1979b, 46: 571-580.

Arnolds, D.E.A.T., Lopes da Silva, F.H., Aitink, J.W. and Kamp, A. Hippocampal EEG correlates of stimulus-response tasks and of sexual behaviour. Electroenceph. clin. Neurophysiol., 1979c, 46: $581-591$.

Grastyán, E., Lissák, K, Madarasz, I. and Donhoffer, H. Hippocampal electrical activity during the development of conditioned reflexes. Electroenceph. clin. Neurophysiol., 1959, 11: 409-430.

Halgren, E., Babb, T.L. and Crandall, P.H. Human hippocampal formation EEG desynchronies during attentiveness and movement. Electroenceph. clin. Neurophysiol., 1978, 44:778-781.

Kemp, J.R.and Kaada, B.R. The relation of hippocampal theta activity to arousal, attentive behaviour and somato-motor movements in unrestrained cats. Brain Res., 1975, 95: 323-342.

Lopes da Silva, F.H, and Kamp, A. Hippocampal theta frequency shifts and operant behaviour. Electroenceph. clin. Neurophysiol,, 1969, 26: $133--143$.

Lopes da Silva, F.H., van Hulten, K., Lommen, J.G., Storm van Leeuwen, W., van Veelen, C.W.M. and Vliegenthart, W. Automatic detection and localization of epileptic foci. Electroenceph. clin. Neurophysiol., 1977, 43: 1--13.

O'Keefe, J. and Nadel, L. The Hippocampus as a Cognitive Map. Clarendon, Oxford, 1978: 381426 . 